\title{
Kemampuan Komunikasi Matematis Melalui Model Reciprocal Teaching Berbantuan Media Interaktif
}

\author{
Ni Kadek Natia Mahadewi ${ }^{1}$, I Made Ardana ${ }^{2}$, Ni Made Sri Mertasari ${ }^{3}$ \\ ${ }^{1}$ Program Studi Pendidikan Matematika, Universitas Pendidikan Ganesha, Singaraja, \\ Indonesia; ${ }^{*}$ kadek.natiamahadewi@gmail.com; ${ }^{2}$ ardanaimade@yahoo.com; \\ ${ }^{3}$ srimertasarinimade@yahoo.co.id
}

Info Artikel: Dikirim: 13 Juni 2020; Direvisi: 16 September 2020; Diterima: 21 September 2020 Cara sitasi: Mahadewi, N. K. K., Ardana, I. M., \& Mertasari, N. M. S. (2020). Kemampuan Komunikasi Matematis Melalui Model Reciprocal Teaching Berbantuan Media Interaktif. JNPM (Jurnal Nasional Pendidikan Matematika), 4(2), 338-350.

\begin{abstract}
Abstrak. Penelitian ini bertujuan untuk menguji pengaruh dari model Reciprocal Teaching yang berbantuan media interaktif terhadap kemampuan komunikasi matematis siswa kelas VIII SMP di Kediri. Penelitian ini memberikan solusi yaitu menerapkan model Reciprocal Teaching berbantuan media interaktif atas kendala dalam penerapan model Reciprocal Teaching dalam pembelajaran dimana tidak semua siswa dapat memahami materi matematika hanya dengan membaca. Penelitian ini menggunakan metode eksperimen semu, dengan post test only control group design. Sampel penelitiannya sebanyak 133 siswa kelas VIII salah satu SMP Negeri di Kediri. Pengumpulan data menggunakan tes, data diuji dengan menggunakan uji-t. Hasil penelitian menunjukkan bahwa terdapat perbedaan secara signifikan pada rata-rata hasil post test kelompok kontrol dan kelompok eksperimen, dimana rata-rata dari kelompok eksperimen lebih besar daripada ratarata kelompok kontrol. Sehingga model Reciprocal Teaching berbantuan media interaktif mempengaruhi kemampuan komunikasi matematis siswa.
\end{abstract}

Kata kunci: Reciprocal Teaching, media interaktif, kemampuan komunikasi matematis.

\begin{abstract}
This study examines the effect of interactive media's reciprocal teaching model on the mathematical communication skills of eighth-grade students of Junior High School in Kediri. This study provides a solution, namely applying the reciprocal teaching model assisted by interactive media for obstacles in applying the reciprocal teaching model in learning. Not all students can understand the mathematical material just by reading. This study used a quasi-experimental method, with a post-test only control group design. The research sample was 133 students of class VIII of a State Junior High School in Kediri. Data collection using tests, data tested using the t-test. The results showed a significant difference in the control group's average post-test results and the experimental group. The average of the experimental group was greater than the control group's average. So that the
\end{abstract}


interactive media assisted reciprocal teaching model affects students' mathematical communication skills.

Keywords: Reciprocal Teaching model, interactive media, mathematical communication skills.

\section{Pendahuluan}

Matematika dipandang sebagai suatu pengetahuan yang wajib dimiliki untuk dapat mengembangkan masyarakat (Olteanu \& Olteanu, 2012). Salah satu kemampuan yang perlu dimiliki siswa dalam belajar matematika adalah kemampuan komunikasi. Kemampuan komunikasi penting dimiliki oleh siswa dalam menyampaikan gagasan, mendeskripsikan, dan mendiskusikan konsep-konsep matematika sehingga ketika kemampuan komunikasi matematisnya baik maka siswa akan mampu membangun konsepnya sendiri serta mampu menyampaikannya kepada orang lain secara jelas dan terstruktur (Lomibao, Luna, \&Lamaco, 2016). Kemampuan komunikasi matematis siswa baik apabila siswa mampu untuk menyampaikan gagasan matematiknya dan mampu memecahkan permasalahan matematik (Elida, 2012).

Baroody (Ansari, 2016) menyatakan bahwa komunikasi dalam matematika sangat penting untuk dikembangkan karena mathematics as language, yang memiliki makna bahwa matematika digunakan sebagai sarana untuk mengkomunikasikan berbagai ide secara jelas, tepat, dan cermat; dan juga karena mathematics learning as sosial activity, yang bermakna bahwa matematika digunakan dalam aktivitas sosial dan mewadahi terjadinya interaksi antar siswa atau pun interaksi guru dan siswa.

Kenyataan yang ditemukan di lapangan menunjukkan kemampuan komunikasi matematis siswa di Indonesia masih rendah. Hal tersebut didukung oleh beberapa hasil penelitian yang menunjukkan kemampuan komunikasi matematis siswa masih rendah (Pane, Jaya, \& Lubis, 2018; Wijayanto, Fajriah, \& Anita, 2018; Zulkarnain, 2013). Kemampuan siswa dalam komunikasi matematis juga dapat diketahui dari hasil belajar matematika. Berdasarkan penelitian yang telah dilakukan oleh Tammi dalam (Astuti \& Leonard, 2015) menemukan adanya pengaruh kemampuan komunikasi matematis terhadap hasil belajar matematika siswa. Dimana, siswa dengan kemampuan komunikasi matematis tinggi akan mampu mencapai hasil belajar yang tinggi pula. Begitu sebaliknya, siswa dengan kemampuan komunikasi matematis rendah, akan menyebabkan hasil belajarnya rendah. Didukung oleh Ratumanan dalam (Astuti \& Leonard, 2015) yang menyatakan bahwa kemampuan siswa dalam berkomunikasi 
sangat penting sebagai hasil belajar yang terdapat dalam salah satu kompetensi lintas kurikulum (kurikulum berbasis kompetensi).

Berdasarkan uraian di atas, hasil belajar matematika rendah karena kemampuan komunikasi matematis siswa kurang, dimana dalam proses belajar ketika memahami materi terjadi suatu proses komunikasi sehingga siswa bisa memahami apa yang dipelajarinya. Proses komunikasi yang dimaksudkan adalah proses tersampaikannya pesan dari bahan ajar kepada siswa dan juga proses bagaimana siswa mengkaitkan antara bahasa dalam bahan ajar dengan ide yang didapatkannya lalu menuangkannya ke dalam simbol-simbol matematika secara tertulis atau pun lisan (Yuniarti, 2013). Karena itulah siswa memerlukan kemampuan komunikasi matematis untuk bisa memahami materi pelajaran dengan baik agar hasil belajar yang maksimal dapat tercapai.

Model Reciprocal Teaching mengkaitkan adanya hubungan antar siswa dalam kelompok atau pun antara siswa dengan guru untuk memaknai suatu materi (Elizabeth, 2010). Kemudian disampaikan bahwa Reciprocal Teaching adalah salah satu model pembelajaran yang dalam proses pembelajarannya menggunakan metode diskusi berdasarkan strategi pemahaman membaca, scaffolding, dan interaksi social (Ahmadi \& Gilakjani, 2012). Kegiatan pembelajaran dalam Reciprocal Teaching ini siswa memegang peran sebagai "guru" dan mengambil alih tugas guru untuk mengajar teman-temannya. Sedangkan peran guru sebagai pemberi contoh, pemberi kemudahan yaitu sebagai fasilitator, dan pembimbing yang melakukan scaffolding.

Westera menyatakan bahwa terdapat tiga tujuan dari model Reciprocal Teaching (Mcallum \& Auckland, 2014). Pertama, Reciprocal Teaching dijadikan petunjuk dalam penerapan empat strategi pemahaman untuk mengembangkan kemampuan pemahaman yang baik. Kedua, Reciprocal Teaching digunakan sebagai proses keterlibatan interaksi untuk mengembangkan kemampuan komunikasi sesama siswa mau pun antara siswa dengan guru. Ketiga, Reciprocal Teaching sebagai media untuk latihan menggunakan berbagai sudut pandang orang lain ketika memecahkan suatu permasalahan. Menurut penelitian yang dilakukan oleh Palincsar \& Brown tahun 1984 digunakannya model Reciprocal Teaching dalam pembelajaran dapat membantu siswa dalam memahami bacaan dengan mengajarkan empat strategi yaitu: clarifyng, predicting, questioning, dan summarizing (Yang, 2010). Pembelajaran dengan model Reciprocal Teaching yang dimaksudkan dalam penelitian ini yaitu mengikuti tahapan strategi menurut Donna Dyer 
dan Menurut Palincsar \& Brown (Yang, 2010), yaitu: summarizing, questioning, clarifying, predicting.

Pertama, summarizing (merangkum). Pada tahap ini siswa dilatih untuk menemukan informasi penting dalam bacaan, mengerti makna bacaan, dan menemukan kata-kata baru (Ahmadi \& Ismail, 2012). Kedua, questioning (membuat pertanyaan). Pada tahap ini siswa dituntun membuat pertanyaan berdasarkan pemahamannya sendiri setelah membaca materi yang diberikan. Kegiatan tersebut dapat membantu siswa untuk memahami isi bacaan dan siswa juga dapat mengecek pemahamannya sendiri (Chen \& Kong, 2017). Ketiga, clarifyng (mengklarifikasi). Pada tahap ini siswa mencari tahu kebenaran dari apa yang telah dipahami dan dibuatnya, mencari solusi dari hal yang belum dipahami, meningkatkan pemahaman agar bisa menyampaikan hasil diskusi dan berargumen (Chen \& Kong, 2017). Keempat, Predicting (memprediksi). Pada tahap ini siswa dilatih untuk memprediksi atau menduga isi bacaan berdasarkan pengetahuan sebelumnya, memprediksi kemungkinan isi bacaan dengan judul atau ilustrasi grafik, serta memprediksi isi bacaan berikutnya sesuai dengan deskripsi pada bacaan sebelumnya (Chen \& Kong, 2017).

Berdasarkan pemaparan tersebut, model Reciprocal Teaching ini mempunyai kelebihan yang dapat digunakan untuk meningkatkan kemampuan komunikasi matematis. Namun, menurut penelitian yang dilakukan oleh (Permatasari, Gunowibowo, \& Coesamin, 2017) menemukan beberapa kendala pada saat menerapkan model Reciprocal Teaching untuk meningkatkan kemampuan komunikasi matematis siswa, diantaranya: (1) tidak semua siswa bisa paham materi pelajaran hanya dengan membaca, (2) kekurangan alokasi waktu. Berdasarkan kendala tersebut maka pada penelitian ini penulis memberikan solusi terhadap kendala di atas, yaitu menerapkan model Reciprocal Teaching dengan berbantuan media interaktif agar siswa tertarik untuk belajar dan membaca sehingga siswa mampu mengerjakan LKS yang diberikan pada saat pembelajaran.

Media pembelajaran merupakan semua hal yang bisa dipakai dalam proses penyampaian informasi atau pesan sehingga dapat menumbuhkan kemauan dan motivasi belajar siswa. Rivai \& Sudjana (2005) menyatakan media pembelajaran bermanfaat dalam proses belajar, karena dapat membuat pembelajaran menjadi lebih menarik sehingga siswa termotivasi untuk belajar, dapat membuat makna dari bahan pelajaran menjadi lebih jelas sehingga siswa lebih mudah paham dan tercapainya tujuan dalam pembelajaran, proses pembelajaran lebih bervariasiktivitas belajar siswa 
menjadi semakin banyak (mengamati, mengerjakan, mempresentasikan, dan memerankan).

Proses pembelajaran menggunakan media interaktif membantu siswa untuk memahami dan membangun pengetahuannya secara mandiri karena penyampaian materi pelajaran menggunakan berbagai mode yang mencakup informasi secara visual dan pendengaran (Ananga \& Akayuure, 2016). Pesatnya perkembangan teknologi saat ini menyebabkan penggunaan media dalam pembelajaran termasuk video interaktif membuat pelajaran lebih menarik (Fadde \& Sullivan, 2013). Selain itu, penggunaan media interaktif dalam pembelajaran juga dapat meningkatkan keterlibatan siswa dalam proses belajar dan meningkatkan kemampuannya dalam memahami pelajaran melalui video (Benkada \& Moccozet, 2017). Berdasarkan pemaparan tersebut, digunakannya media interakatif dalam pembelajaran akan sangat membantu proses pembelajaran. Jenis media pembelajaran yang digunakan pada penelitian ini yaitu multimedia interaktif yang di dalamnya terdapat video pembelajaran.

Penggunaan media interaktif yang berupa video pembelajaran dapat membantu dalam mengatasi adanya perbedaan kemampuan yang dimiliki siswa pada saat memahami materi pelajaran. Sehingga siswa yang tidak bisa memahami materi hanya dengan membaca akan terbantu dengan digunakannya media interaktif dalam pembelajaran tersebut. Sesuai dengan hasil dari penelitian menunjukkan bahwa penggunaan media dalam pembelajaran dapat memotivasi dan mendorong minat belajar siswa (Supardi, 2014; Nuritno, Raharjo, \&Winarso, 2019). Oleh karena itu tujuan penelitian ini adalah untuk mengetahui kemampuan komunikasi matematis siswa yang dibelajarkan dengan menggunakan model Reciprocal Teaching berbantuan media interaktif.

\section{Metode}

Penelitian ini adalah penelitian semu dengan post test only control group design. Penelitian ini diadakan di suatu SMP negeri di Kediri, Bali. Populasi penelitianyaitu semua siswa kelas VIII yang terbagi ke dalam 6 kelas homogen dengan jumlah 197 orang siswa. Kemudian untuk menentukan banyaknya sampel minimal digunakan rumus Slovin (Noor, 2012). Terpilih sampel sebanyak 133 orang dengan teknik cluster random sampling. Siswa kelas VIII digunakan sebagai populasi karena materi pelajaran yang digunakan dalam penelitian adalah bangun ruang sisi datar (materi kelas VIII) sesuai dengan video interaktif yang tersedia dan sudah diujikan. 
Instrumen yang digunakan adalah tes yang berbentuk soal uraian (essay) yang berjumlah delapan butir soal bangun ruang sisi datar. Sebelum instrumen digunakan, terlebih dahulu dilakukan uji coba untuk menjamin kualitas instrumen yang digunakan dengan melakukan analisis. Hasil uji validitas menunjukkan terdapat tujuh soal valid dari delapan soal, reliabilitasnya sebesar 1,00; berdasarkan tingkat kesukarannya terdapat lima soal kategori sedang, satu soal mudah, dan dua sukar, serta berdasarkan daya pembeda terdapat empat soal dalam kategori cukup, tiga soal kategori baik dan satu soal jelek.

Setelah dilakukan analisis terhadap hasil uji coba, selanjutnya dilakukan tes akhir pada kelas sampel untuk mengetahui kemampuan komunikasi matematis siswa. Untuk mengetahui data subjek penelitian berdistribusi normal dan homogen maka dilakukan uji normalitas dengan uji Liliefors dan uji homogenitas dengan uji Fisher. Pengujian hipotesis pada penelitian ini dengan uji t satu ekor karena pada penelitian ini membandingkan dua model pembelajaran yang akan menghasilkan satu model yang lebih baik untuk digunakan. Kriteria pengujian dalam uji $\mathrm{t}$ adalah $\mathrm{H}_{0}$ ditolak jika $t_{\text {hitung }} \geq$ $t_{\text {tabel }}$ dimana $t_{\text {tabel }}=t_{(1-\pi)(d k)}$ didapat dari tabel distribusi $\mathrm{t}$ pada taraf signifikansi $(\alpha) 5 \%$ derajat kebebasan $\mathrm{dk}=\left(\mathrm{n}_{1}+\mathrm{n}_{2}-2\right)$.

Pelaksanaan pembelajaran menggunakan langkah-langkah Reciprocal pada tabel 1.

Tabel 1. Langkah-langkah Reciprocal Teaching Berbantuan Media Interaktif

\begin{tabular}{ll}
\hline Kegiatan Guru & Kegiatan Siswa \\
\hline $\begin{array}{l}\text { Summarizing } \\
\text { Mumahinta siswa membuat rangkuman materi di }\end{array}$ & $\begin{array}{l}\text { Summarizing } \\
\text { Mempelajari video dan membuat } \\
\text { rangkuman }\end{array}$ \\
$\begin{array}{l}\text { Questioning } \\
\text { Memberi kesempatan siswa untuk bertanya jika } \\
\text { terdapat hal yang belum dipahami }\end{array}$ & $\begin{array}{l}\text { Questioning } \\
\text { dipananyakan hal yang belum }\end{array}$ \\
$\begin{array}{l}\text { Clarifying } \\
\text { Mengarahkan siswa untuk menyampaikan } \\
\text { pemahamannya dan guru mengklarifikasi jika } \\
\text { terdapat kekeliruan }\end{array}$ & $\begin{array}{l}\text { Clarifying } \\
\text { Menyampaikan pemahamannya }\end{array}$ \\
$\begin{array}{l}\text { Predicting } \\
\text { Memberikan siswa kesempatan untuk } \\
\text { mengerjakan dan menduga soal-soal yang } \\
\text { berkaitan dengan materi yang telah dipelajari }\end{array}$ & $\begin{array}{l}\text { dipelajari ataupun materi yang } \\
\text { ataupun materi yang berikutnya. }\end{array}$ \\
\hline
\end{tabular}


Untuk menanggulangi kekurangan waktu dalam pembelajaran, maka pada penelitian ini tahapan dalam pelaksanaan model Reciprocal Teaching (tahap 1) yaitu summarizing akan dilaksanakan di luar jam pelajaran sekolah. Sehingga siswa wajib mempelajari dan merangkum materi pelajaran sebelum pertemuan di kelas diadakan.

\section{Hasil dan Pembahasan}

Hasil analisis data kemampuan komunikasi matematis siswa adalah sebagai berikut.

Tabel 2. Hasil Analisis Data Kemampuan Komunikasi Matematis

\begin{tabular}{llll}
\hline No & Variabel & \multicolumn{2}{c}{ Post Test } \\
& & Kelompok Eksperimen & Kelompok Kontrol \\
\hline 1 & Jumlah Sampel & 64 & 69 \\
2 & Rata-Rata & 60,09375 & 32,75362 \\
3 & Standar Deviasi & 15,78197 & 18,7306 \\
\hline
\end{tabular}

Tabel 2 menunjukkan bahwa rata-rata skor untuk kelompok eksperimen lebih besar dari pada rata-rata skor kelompok kontrol. Artinya bahwa ratarata skor kemampuan komunikasi matematis siswa yang dibelajarkan dengan menggunakan model Reciprocal Teaching berbantuan media interaktif lebih baik daripada rata-rata skor kemampuan komunikasi matematis siswa yang dibelajarkan dengan pembelajaran konvensional.

Berdasarkan hasil uji normalitas dan uji homogenitas dengan menggunakan software excel, diperoleh bahwa data kemampuan komunikasi matematis siswa untuk kelas kontrol dan kelas eksperimen berdistribusi normal dan homogen. Kemudian dilakukan uji hipotesis dengan menggunakan Uji-t. Hasil perhitungannya diperoleh $t_{\text {hitung }}$ sebesar 9,06 dan $t_{\text {tabel }}$ sebesar 1,978239. Jika dibandingkan maka $t_{\text {hitung }}>t_{\text {tabel }}$ sehingga tolak $H_{0}$. Artinya bahwa kemampuan komunikasi matematis siswa yang dibelajarkan dengan menggunakan model Reciprocal Teaching lebih baik daripada kemampuan komunikasi matematis siswa yang dibelajarkan dengan pembelajaran konvensional.

Pada penelitian yang telah dilakukan penulis, model Reciprocal Teaching diawali dari tahap summarizing (merangkum). Dalam tahapan ini siswa dibantu oleh media interaktif berupa video pembelajaran. Multimedia interaktif adalah bagian dari media yang didefinisikan sebagai alat perantara yang di dalamnya berisi suara, gambar, dan kata-kata untuk kegiatan pembelajaran demi tercapainya tujuan (Amir, Hasanah, \& Mustofa, 2018). 
Dalam penelitian ini multimedia interaktif yang digunakan dibuat dengan menyertakan tanggapan dari pengguna secara aktif. Selain itu, terdapat komponen yang terpenting di dalamnya yaitu adanya interaktive link sehingga pengguna dapat menggunakan mouse atau objek pada layar (seperti button) sesuai kehendaknya yang akan menyebabkan program tersebut berjalan sesuai dengan perintah tertentu. Siswa diberikan video pembelajaran tiga hari sebelum pertemuan kelas diadakan. Tahap ini menuntut siswa menyatakan kembali ide utama materi dengan kalimatnya sendiri untuk memastikan bahwa mereka sudah mengerti (Cooper \& Greive, 2009). Masing-masing siswa wajib membuat rangkuman materi sebelum kegiatan pembelajaran di kelas dilaksanakan. Rangkuman tersebut dibuat berdasarkan video pembelajaran yang telah diberikan agar siswa dapat mengidentifikasi dan mengintegrasikan informasi penting yang terdapat dalam materi. Sebelum merangkum, terlebih dahulu siswa menyimak video pembelajaran agar dapat menyelesaikan rangkumannya sehingga kemampuan komunikasinya akan berkembang karena dengan adanya kegiatan merangkum tersebut melatih siswa untuk menuliskan dengan terstruktur apa yang telah dipahaminya.

Tahap kedua, membuat daftar pertanyaan (questioning) untuk mengecek pemahaman siswa. Pertanyaan ini dibuat ketika siswa mulai mengidentifikasi informasi penting yang terdapat pada materi yang diberikan (Ahmad \& Lanteri, 2017). Pada tahapan ini siswa diberikan LKS dan mendiskusikannya dengan kelompok masing-masing. Dalam kelompok, setiap siswa bergiliran untuk memimpin diskusi sedangkan guru sebagai fasilitator (Qohar \& Sumarmo, 2013). Pada awal kegiatan pembelajaran, guru memimpin diskusi dan kemudian secara bertahap peran guru dialihkan kepada siswa untuk memimpin diskusi secara bergiliran di setiap pertemuannya (Lavarino, 2016). Berdasarkan pengamatan penulis pada saat penelitian, siswa menuliskan pertanyaan-pertanyaan yang belum dipahaminya untuk nantinya ditanyakan kepada kelompok lain atau guru. Apabila siswa sudah membuat daftar pertanyaan artinya siswa sudah benarbenar belajar sehingga mengetahui bagian mana yang belum dipahaminya. Hal tersebut mendorong berkembangnya kemampuan komunikasi matematis siswa karena untuk bisa membuat pertanyaan-pertanyaan siswa harus mampu memahami, menginterpretasi, mengevaluasi ide-ide matematis yang terdapat dalam materi pelajaran. Kemudian pertanyaanpertanyaan yang sudah dibuat didiskusikan terlebih dahulu dengan kelompok masing-masing dan guru akan membantu menjawab pertanyaanpertanyaan apabila masih ada pertanyaan yang belum dapat diselesaikan dalam kelompok. 
Tahap ketiga, mengklarifikasi (clarifying) agar siswa dapat menyampaikan temuannya ketika mempelajari materi yang diberikan. Selain itu siswa juga dituntut untuk mengklarifikasi dan memodifikasi konsep yang ditemukan (Andira, Santoso, \& Yusuf, 2018). Siswa yang dipilih secara acak mempresentasikan hasil diskusi kelompoknya. Berdasarkan pengamatan peneliti, dengan adanya tahapan ini siswa berusaha memahami materi dengan sebaik-baiknya karena setiap siswa dituntut untuk bisa menyampaikan gagasannya dan juga memberikan argumen-argumen terhadap gagasan temannya atau kelompok lain. Siswa juga harus bisa mempertahankan argumennya ketika terjadi perbedaan argumen. Kagiatan tersebutlah yang kemudian dapat membuat kemampuan siswa dalam aspek kemampuan komunikasi matematis dapat meningkat karena siswa sudah mampu memahami, menginterpretasi, mengevaluasi gagasan matematis yang ditemukannya melalui tulisan atau dalam bentuk lainnya, serta meningkatkan kemampuannya dalam hal penggunaan simbol matematika dan strukturnya untuk menyampaikan temuannya selama pembelajaran berlangsung.

Pada tahap terakhir, memprediksi (predicting). Pada tahap ini siswa memprediksi permasalahan yang mungkin muncul dalam soal-soal berdasarkan pengetahuan dan pengalaman yang sudah dimilikinya (Pilten, 2016). Dalam pembelajaran di kelas siswa diberikan soal-soal berdasarkan atas penggabungan materi yang sedang dipelajarinya dengan materi yang sudah dipelajarinya sebelumnya. Berdasarkan pengamatan penulis, siswa mampu mengerjakan soal-soal yang diberikan melalui diskusi kelompok. Tentunya untuk dapat mengerjakan soal-soal tersebut siswa harus benarbenar memahami materi-materi yang telah dipelajarinya. Kegiatan tersebut melatih kemampuan pemahaman siswa, menjelaskan ide-ide matematis yang ditemukannya, serta dapat menggambarkan ide tersebut melalui jawaban tertulis sehingga kemampuan komunikasi matematisnnya meningkat.

Berdasarkan pengamatan penulis selama penelitian, penggunaan model Reciprocal Teaching dalam pembelajaran berdampak positif terhadap kemampuan komunikasi matematis siswa karena model ini memiliki tiga ciri khas: (1) Scaffolding, (2) menggunakan empat strategi pemahaman (summarizing, questioning, clarifying, predicting), (3) interaksi sosial (Juliana, 2016) sehingga dapat membantu siswa untuk mencapai tujuan pembelajaran (Mulyono, Asmawi, \&Nuriah, 2018). Pada pembelajaran dengan model Reciprocal Teaching berbantuan media interaktif memungkinkan terjadinya 
suatu sistem pembelajaran tutor sebaya yang dapat membantu peserta didik yang tidak berani dalam memberi tanggapan dan pendapat nantinya dapat berinteraksi dengan teman sekelasnya (Vahlia \& Sudarman, 2015). Selain itu, digunakannya model Reciprocal Teaching berbantuan media Interaktif dalam pembelajaran juga sejalan dengan teori kontruktivisme (Erwanto, Maryatmi, Budiyanto, 2018). Kontruktivisme yang dimaksud adalah dalam pembelajarannya memberikan kebebasan kepada siswa untuk memperoleh dan membangun pengetahuannya secara mandiri sehingga siswa bisa lebih paham dengan konsep-konsep dalam pelajaran dan juga bisa mengkontruksi idenya sendiri dalam bentuk tulisan atau lisan (Rangkuti, 2014). Hal tersebut tampak pada kegiatan siswa ketika siswa belajar dengan menggunakan video pembelajaran secara mandiri yang menuntut siswa agar memahami materi dan membuat rangkuman dengan baik sehingga akan mempengaruhi kemampuan siswa dalam hal komunikasi matematis (Yuniar, Rohaeti, Aryan, 2018). Penggunaan media interaktif dalam pembelajaran sejalan dengan penelitian yang dilakukan Nuritno, Raharjo, dan Winarso (2017) yang menemukan hasil bahwa digunakannya bahan ajar dengan multimedia interaktif ketika belajar matematika mampu mendorong minat dan keaktifan siswa dalam pembelajaran. Selain itu, Gagne \& Briggs (Hardianto, 2005) juga mendefinisikan media sebagai komponen yang terdapat pada lingkungan siswa sehingga dapat merangsang siswa untuk belajar dan dapat menumbuhkan keinginan siswa untuk belajar. Berdasarkan definisi tersebut disimpulkan bahwa dengan penggunaan media dalam pembelajaran memberikan motivasi kepada siswa sehingga siswa mau belajar dan memahami pelajarannya dengan sungguh-sungguh.

Analisis terhadap hasil tes kemampuan komunikasi matematis siswa menunjukkan bahwa kemampuan komunikasi matematis siswa dalam kelas eksperimen yang dibelajarkan dengan model Reciprocal Teaching berbantuan media interaktif lebih baik daripada kemampuan komunikasi matematis siswa dalam kelas kontrol yang dibelajarkan dengan pembelajaran konvensional karena pada pembelajaran dengan Reciprocal Teaching berbantuan media interaktif siswanya lebih aktif sehingga kemampuan komunikasi matematisnya meningkat. Sejalan dengan Baharun (2015) dalam penelitiannya menyebutkan bahwa pembelajaran yang lebih banyak melibatkan siswa dalam mencari berbagai informasi dan pengetahuan adalah pembelajaran aktif yang dapat membantu mengembangkan kemampuan kognitif siswa, salah satunya kemampuan komunikasi matematis. Sedangkan pada pembelajaran konvensional peran guru yang mendominasi pembelajaran, dimana siswa hanya mendengarkan penjelasan dari guru, mengerjakan LKS dan membagi tugas agar proses pengerjaan 
lebih cepat. Hal tersebut dapat membatasi motivasi dan kreativitas belajar siswa sehingga menghambat berkembangnya kemampuan komunikasinya. Selain itu, hasil analisis terhadap hasil post-test pada kelompok kontrol juga menunjukkan bahwa kemampuan komunikasi matematisnya masih rendah. Terlihat dari banyaknya siswa yang mendapat nilai nol ketika tes dilaksanakan. Berdasarkan pengamatan peneliti, hal tersebut disebabkan oleh kurangnya tanggung jawab siswa pada pelajaran dan juga pada pembelajarannya tidak ada tuntutan yang membuat siswa memahami materi dengan sungguh-sungguh sehingga siswa hanya sekedar belajar dan ketika tes tidak bisa menjawab soal-soal yang diberikan.

Secara umum pelaksanaan pembelajaran menggunakan model Reciprocal Teaching berbantuan media interaktif sudah berjalan sesuai dengan rencana peneliti.Hal ini diperkuat dengan hasil post test yang menyatakan rata-rata skor kemampuan komunikasi matematis siswa yang dibelajarkan dengan model Reciprocal Teaching berbantuan media interaktif lebih baik daripada rata-rata skor kemampuan komunikasi matematis siswa yang dibelajarkan dengan pembelajaran konvensional.

\section{Simpulan}

Kemampuan komunikasi matematis siswa yang dibelajarkan dengan menggunakan model Reciprocal Teaching berbantuan media interaktif lebih baik daripada kemampuan komunikasi matematis siswa yang dibelajarkan dengan pembelajaran konvensional. Pengujicobakan model Reciprocal Teaching berbantuan media interaktif pada aspek kognitif lainnya perlu dilakukan, seperti pemahaman konsep dan kemampuan pemecahan masalah, Guru matematika dapat menerapkan model Reciprocal Teaching berbantuan media interaktif ini dalam pembelajaran di kelas mengingat model ini berpengaruh positif terhadap kemampuan komunikasi matematis siswa.

\section{Daftar Pustaka}

Ahmad, T., \& Lanteri, C. (2017). Implementation of Reciprocal Teaching Models to Increase The Capability of Writing Definition and Theorem in Simbolic Form. JETL (Journal Of Education, Teaching and Learning), 2(1), 21-26.

Ahmadi, M. R., \& Gilakjani, A. P. (2012). Reciprocal teaching strategies and their impacts on English reading comprehension. Theory and Practice in Language Studies, 2(10), 20532060. https://doi.org/10.4304/tpls.2.10.2053-2060

Ahmadi, M. R., \& Ismail, H. N. (2012). Reciprocal Teaching Strategy as an Important Factor of Improving Reading Comprehension. Journal of Studies in Education, 2(4), 1183611841. https://doi.org/10.5296/jse.v2i4.2584

Amir, M. F., Hasanah, F. N., \& Musthofa, H. (2018). Interactive multimedia based 
mathematics problem solving to develop students' reasoning. International Journal of Engineering and Technology(UAE), 7(14), 272-276.

Ananga, \& Akayuure. (2016). Integrating interactive multimedia into mathematics course modules for distance education. African Journal of Educational Studies in Mathematics and Sciences, 12(0), 35-44.

Andira, T., Santoso, B., \& Yusup, M. (2018). Penerapan model pembelajaran reciprocal teaching ditinjau dari kemampuan penalaran matematis peserta didik pada materi bangun datar segiempat Applying of reciprocal teaching learning model viewed from students ' mathematical reasoning on quadrilateral mat. Pythagoras, 13(1), 88-98.

Ansari, B. (2016). Komunikasi Matematik Strategi Berfikir Dan Manajemen Belajar: Konsep Dan Aplikasi. Banda Aceh: Penerbit PeNA.

Astuti, A., \& Leonard, L. (2015). Peran Kemampuan Komunikasi Matematika Terhadap Prestasi Belajar Matematika Siswa. Formatif: Jurnal Ilmiah Pendidikan MIPA, 2(2), 102-110 https://doi.org/10.30998/formatif.v2i2.91

Baharun, H. (2015). Jurnal Pendidikan Pedagogik, Vol. 01 No. 01 Januari-Juni 2015. Penerapan Pembelajaran Active Learning Untuk Meningkatkan Hasil Belajar Siswa Di Madrasah, Jurnal Pendidikan Pedagogik, 1(1), 39-49.

Benkada, C., \& Moccozet, L. (2017). Enriched interactive videos for teaching and learning. Proceedings - 2017 21st International Conference Information Visualisation, IV 2017, November, 344-349. https://doi.org/10.1109/iV.2017.74

Chen, Y., \& Kong, D. (2017). An investigation on factors in the integration of reciprocal teaching into multimedia teaching. Eurasia Journal of Mathematics, Science and Technology Education, 13(1), 133-142. https://doi.org/10.12973/eurasia.2017.00608a

Cooper, T., \& Greive, C. (2009). The Effectiveness of the Methods of Reciprocal Teaching. Teach, 3(1), 45-52.

Elida, N. (2012). Meningkatkan kemampuan komunikasi matematik siswa sekolah menengah pertama melalui pembelajaran think-talk-write (ttw). Jurnal Ilmiah Program Studi Matematika STKIP Siliwangi Bandung, 1(2), 178-185.

Elizabeth, A. (2010). Common Literacy Struggles with College Students: Using the Reciprocal Teaching Technique. JCRL FORUM, 1(1), 110-116.

Erwanto, E., Maryatmi, A. S., \& Budiyanto, A. (2018). The Effects of Reciprocal Teaching Learning Strategy and Self efficacy on Learning Outcomes of Early Childhood (AUD) Mathematical Logic. Al-Jabar: Jurnal Pendidikan Matematika, 9(1), 41-50. https://doi.org/10.24042/ajpm.v9i1.2567

Fadde, P. J., \& Sullivan, P. (2013). Using interactive video to develop pre-service teachers' classroom awareness. Contemporary Issues in Technology and Teacher Education, 13(2), 156-174.

Hardianto, D. (2005). Media Pendidikan Sebagai Sarana Pembelajaran Efektif. Majalah Ilmiah Pembelajaran, 1(1), 95-104.

Juliana. (2016). Teaching Reading Comprehension By Using Reciprocal Teaching Approach. English Education Journal (Program Pascasarjana Universitas Negeri Semarang), 7(2), 260271.

Lavarino, Dio. (2016). Implementasi Model Pembelajaran Reciprocal Teaching Untuk Meningkatkan Kemampuan Berpikir Kritis Dan Hasil Belajar. 6(2), 172-179.

Lomibao, L. S., Luna, C. A., \& Namoco, R. A. (2016). The Influence of Mathematical Communication on Students' Mathematics Performance and Anxiety. American Journal of Educational Research, 4(5), 378-382. https://doi.org/10.12691/education-4-5-3

Mcallum, R., \& Auckland, C. W. (2014). Reciprocal Teaching: Critical Reflection on Practice. 15(1), 26-35. 
Mulyono, D., Asmawi, M., \& Nuriah, T. (2018). The Effect of Reciprocal Teaching, Student Facilitator and Explaining and Learning Independence on Mathematical Learning Results by Controlling the Initial Ability of Students. International Electronic Journal of Mathematics Education, 13(3), 199-205. https://doi.org/10.12973/iejme/3838

Noor, J. 2012. Metodologi Penelitian. Jakarta: Kencana Prenada Media Group.

Nuritno, R., Raharjo, H., \& Winarso, W. (2019). Pengembangan Bahan Ajar Berbasis Multimedia Interaktif. Iformation Technology Engineering Journals. April 2017.

Olteanu, C., \& Olteanu, L. (2012). Equations, functions, critical aspects and mathematical communication. International Education Studies, 5(5), 69-78. https://doi.org/10.5539/ies.v5n5p69

Pane, N. S., Jaya, I., \&, \& Lubis, M. S. (2018). Analisis Kemampuan Komunikasi Matematis Siswa Pada Materi Penyajian Data di Kelas VII MTs Islamiyah Medan T.P 2017/2018. Jurnal AXIOM, Volume VII, 97-109.

Permatasari, D. P., Gunowibowo, P., \& Coesamin, M. (2017). Pengaruh Model Reciprocal Teaching terhadap peningkatan kemampuan komunikasi matematis siswa. Jurnal Pendidikan Matematika Universitas Lampung, 5(1), 1-8.

Pilten, G. (2016). The Evaluation of Effectiveness of Reciprocal Teaching Strategies on Comprehension of Expository Texts. Journal of Education and Training Studies, 4(10), 232-247. https://doi.org/10.11114/jets.v4i10.1791

Qohar, A., \& Sumarmo, U. (2013). Improving Mathematical Communication Ability And Self Regulation Learning Of Yunior High Students By Using Reciprocal Teaching. Journal on Mathematics Education, 4(1), 59-74. https://doi.org/10.22342/jme.4.1.562.59-74

Rangkuti, A. N. (2014). Konstruktivisme dan Pembelajaran Matematika. Darul Ilmi, 2(2), 6176.

Rivai, Ahmad dan Sudjana, N. (2005). Media Pengajaran. Bandung: Sinar Baru.

Supardi, A. (2014). Penggunaan Multimedia Interaktif Sebagai Bahan Ajar Suplemen Dalam Peningkatan Minat Belajar. Jurnal Pendas, 1(2), 161-167.

Vahlia, I., \& Sudarman, S. W. (2015). Penerapan Model Pembelajaran Berbalik (Reciprocal Teaching) Ditinjau Dari Aktivitas Dan Hasil Belajar Siswa. AKSIOMA Journal of Mathematics Education, 4(1), 59-66. https://doi.org/10.24127/ajpm.v4i1.94

Wijayanto, A. D., Fajriah, S. N., \& Anita, I. W. (2018). Analisis Kemampuan Komunikasi Matematis Siswa SMP Pada Materi Segitiga Dan Segiempat. Jurnal Cendekia: Jurnal Pendidikan Matematika, 2(1), 97-104. https://doi.org/10.31004/cendekia.v2i1.36

Yang, Y. F. (2010). Developing a Reciprocal Teaching/Learning System For College Remedial Reading Instruction. Computers and Education, 55(3), 1193-1201. https://doi.org/10.1016/j.compedu.2010.05.016

Yuniar, I., Rohaeti, E. E., \& Soekisno, R. B. A. (2018). Improving Understanding and Mathematical Communication Level and Study Learning With Reciprocal Teaching Approach. (Jiml) Journal of Innovative Mathematics Learning, 1(2), 59-65.

Yuniarti, Y., \& Pendahuluan, A. (2013). Pengembangan kemampuan komunikasi matematis dalam pembelajaran matematika di sekolah dasar. c, 109-114.

Zulkarnain, I. (2013). Kemampuan pemahaman dan Komunikasi Matematis Siswa dalam Pembelajaran Kooperatif Berbasis Konflik Kognitif. Bandung: Universitas Pendidikan Indonesia. 